\title{
Risk Factors for and Outcomes of Bacteremia Caused by Extended-Spectrum ß-Lactamase- Producing Escherichia coli and Klebsiella Species at a Canadian Tertiary Care Hospital
}

\author{
My-Linh Nguyen, Baldwin Toye, Salmaan Kanji, and Rosemary Zvonar
}

\begin{abstract}
Background: Antimicrobial resistance due to production of extendedspectrum ß-lactamases by Escherichia coli and Klebsiella species (ESBL-EK) is concerning. Previous studies have shown that bacteremia due to ESBLproducing organisms is associated with increases in length of stay and/or mortality rate. Rates of infection by ESBL-EK vary worldwide, and regional differences in the prevalence of risk factors are likely. Few Canadian studies assessing risk factors for ESBL-EK infections or the outcomes of empiric therapy have been published.

Objectives: To determine risk factors for and patient outcomes associated with ESBL-EK bacteremia. The appropriateness of empiric antibiotic therapy and the effect of inappropriate empiric therapy on these outcomes were also examined.

Methods: In a retrospective, 1:1 case-control study conducted in a tertiary care hospital between 2005 and 2010, data for 40 patients with ESBL-EK bacteremia were compared with data for 40 patients who had non-ESBL-EK bacteremia.

Results: Of all variables tested, only antibiotic use within the previous 3 months was found to be an independent risk factor for acquisition of ESBL-EK bacteremia (odds ratio 5.2, 95\% confidence interval 1.6-16.9). A greater proportion of patients with non-ESBL-EK bacteremia received appropriate empiric therapy (88\% [35/40] versus $15 \%[6 / 40], p<0.001)$. Time to appropriate therapy was longer for those with ESBL-EK bacteremia ( 2.42 days versus 0.17 day, $p<0.001$ ). Patient outcomes, including length of stay in hospital, admission to the intensive care unit (ICU), length of stay in the ICU (if applicable), and in-hospital mortality were not affected by the presence of ESBL-EK or the appropriateness of empiric therapy.

Conclusions: Previous antibiotic use was a significant, independent risk factor for acquiring ESBL-EK. Thus, prior antibiotic use is an important consideration in the selection of empiric antibiotic therapy and should increase the concern for resistant pathogens.
\end{abstract}

Key Words: extended-spectrum ß-lactamases, risk factors. Escherichia coli, Klebsiella, case-control study

\section{RÉSUMÉ}

Contexte : La résistance aux antimicrobiens attribuable à la production de ß-lactamases à spectre étendu (BLSE) par les espèces Escherichia coli et Klebsiella est préoccupante. Des études antérieures ont démontré que les bactériémies causées par les organismes producteurs de BLSE sont associées à une augmentation de la durée du séjour à l'hôpital ou du taux de mortalité. Les taux d'infection par les espèces E. coli ou Klebsiella productrices de BLSE varient de par le monde et les différences régionales de la prévalence des facteurs de risque sont vraisemblables. Peu d'études canadiennes évaluant les facteurs de risque de ces infections ou les résultats cliniques des antibiothérapies empiriques ont été publiées.

Objectifs : Déterminer quels sont les facteurs de risque des bactériémies à $E$. coli ou à Klebsiella productrices de BLSE ainsi que les résultats cliniques associés à ces bactériémies. De plus, étudier la pertinence de l'antibiothérapie empirique ainsi que l'effet d'une antibiothérapie empirique inappropriée sur ces résultats.

Méthodes : Au cours d'une étude cas-témoins rétrospective d'un ratio de 1 pour 1 et réalisée dans un centre hospitalier de soins tertiaires entre 2005 et 2010, les données de 40 patients présentant une bactériémie à $E$. coli ou Klebsiella productrices de BLSE ont été comparées aux données de patients présentant une bactériémie à organisme non producteur de BLSE.

Résultats : Parmi toutes les variables évaluées, seul l'emploi d'une antibiothérapie dans les trois derniers mois s'est révélé être un facteur de risque indépendant du développement d'une bactériémie à E. coli ou Klebsiella productrices de BLSE (risque relatif approché de 5,2, intervalle de confiance à $95 \%$ de 1,6-16,9). Une plus grande proportion de patients présentant une bactériémie autre que celles à E. coli ou Klebsiella productrices de BLSE ont reçu une antibiothérapie empirique appropriée (88\% [35/40] contre $15 \%[6 / 40], p<0,001)$. Le temps requis pour trouver le traitement adéquat était plus long pour ceux présentant une bactériémie à E. coli ou Klebsiella productrices de BLSE (2,42 jours contre 0,17 jour, $p<0,001)$. La présence des espèces E. coli ou Klebsiella productrices de BLSE de même que la pertinence d'une antibiothérapie empirique n'ont pas eu de répercussion sur les résultats cliniques, notamment la durée du séjour à l'hôpital, l'admission à l'unité des soins intensifs (USI), la durée du séjour à l'USI (le cas échéant) ainsi que le taux de mortalité en hôpital. Conclusions : L'emploi d'une antibiothérapie préalable représentait un important facteur de risque indépendant de la survenue des espèces E. coli ou Klebsiella productrices de BLSE. Ce faisant, l'emploi d'une antibiothérapie préalable représente un facteur important à considérer au moment du choix d'une antibiothérapie empirique et devrait rendre sensible aux dangers des pathogènes résistants.

Mots clés : ß-lactamases à spectre étendu, facteurs de risque, Escherichia coli, Klebsiella, étude cas-témoins 


\section{INTRODUCTION}

Cirst reported in the early 1980 s, organisms that produce Cextended-spectrum B-lactamases (ESBLs) can render penicillins, oxyimino-cephalosporins (e.g., cefotaxime, ceftazidime, and ceftriaxone), and monobactams (e.g., aztreonam) ineffective. ${ }^{1,2}$

The most recent Canadian data on the prevalence of organisms producing ESBLs comes from the Canadian Hospital Ward Antibiotic Resistance Surveillance program, which assesses antimicrobial susceptibility in pathogens from tertiary care medical centres. Estimates from 2011 comprising data from 8 hospitals across Canada showed rates of Escherichia coli and Klebsiella species producing extended-spectrum ß-lactamases (ESBL-EK) of $7.1 \%$ and $4.0 \%$, respectively. ${ }^{3}$ ESBL-EK infections are of international concern, and their rates are increasing both in Canada and around the world, including in the community setting. ${ }^{2,3}$ As antimicrobial resistance increases, it is becoming apparent that the appropriate use of antimicrobial agents (i.e., antimicrobial stewardship) is needed to optimize patient outcomes and to preserve the susceptibility of organisms to available antibiotics. It is thus necessary to determine any risk factors that may predispose a patient to infections caused by multidrugresistant organisms and thereby to improve the selection of empiric therapy.

A systematic literature search revealed that several studies examining empiric antibiotic therapy and related clinical outcomes and/or potential risk factors for ESBL-EK infections have been conducted in various countries. Because the rates of infection with ESBL-EK vary, regional differences may exist in terms of the factors predisposing patients to these infections. Only 3 studies from Canada assessing these objectives have been published. ${ }^{4-6}$ The current study was undertaken to determine the risk factors for and the outcomes of patients with ESBL-EK bacteremia in a tertiary care Canadian hospital.

\section{METHODS}

Approval was obtained from The Ottawa Health Science Network Research Ethics Board for this retrospective casecontrol study.

\section{Study Design and Participants}

All patients at least 18 years of age who were admitted to The Ottawa Hospital between January 1, 2005, and December 31, 2010, with a positive result on blood culture for ESBL-EK were included as cases. The Ottawa Hospital is a tertiary care teaching hospital with 1000 acute care beds at 2 campuses. Services include medicine, surgery, oncology, trauma, and intensive care. For patients with multiple episodes of ESBL-EK bacteremia during this period, only the first case was included in the analysis. Controls were patients with bacteremia caused by E. coli or Klebsiella species not producing ESBL (non-ESBL-EK).
The cases were matched 1:1 to controls with the same organism (i.e., same genus and species) isolated closest in time to the case patients. Bacteria were identified using standard microbiological methods. ESBL-producing organisms were identified according to the methods recommended by the Clinical and Laboratory Standards Institute. ${ }^{7}$

\section{Data Collection}

Data were collected using the hospital's electronic database software and patient charts. To ensure the validity of the collected data in terms of interobserver variability, data for 10 patients were reviewed by 2 independent reviewers and the findings compared.

Data collected included patient demographic characteristics (age, sex), residence before admission (home or long-term care facility), and admitting campus. The presence of comorbid conditions, categorized by body system, was collected to calculate a Charlson score for each patient. ${ }^{8}$ A higher Charlson score indicates an increase in cumulative risk of death. Previous antibiotic use and history of travel to Europe, South Asia, or South East Asia within the 90 days preceding bacteremia, as stated in the hospital chart, were also recorded. Antibiotic therapy started before admission to hospital was not included as "previous antibiotic use" if the antibiotic had clearly been started to treat the current infection, as it is unlikely that such antibiotics would affect the causative organism. Mechanical ventilation and presence of a central venous or indwelling urinary catheter at the time the blood sample was drawn for culture were noted. Culture results, including dates of sampling, causative organisms, and susceptibility, were collected. The potential source of infection was recorded according to identification of the same organism in a nonblood specimen. If no positive culture results from an alternative site were available, then the potential source of infection was recorded on the basis of progress notes in the patient's chart. If no potential source of infection was mentioned, the bacteremia was categorized as being of "unknown origin". Empiric antibiotic therapy, changes in treatment, and time of change in treatment (if applicable) were also collected. If the time of an order was not indicated, the time was estimated from the timing of surrounding orders and/or the time of documentation by the ward clerk or nurse.

For nosocomial cases, the length of the hospital stay before identification of bacteremia and the patient's location (medical ward, surgical ward, or intensive care unit [ICU]) at the time of bacteremia were recorded.

Additional data collected for outcome measures included total length of hospital stay (from the date on which the blood sample yielding a positive culture result was drawn), admission to the ICU, length of stay in the ICU (if applicable; from date the blood sample was drawn), and in-hospital mortality.

Bacteremia was categorized according to whether onset occurred in the community or in a noncommunity setting. Community-onset bacteremia was defined as bacteremia that was 
present before admission to hospital or that was identified within $48 \mathrm{~h}$ after admission. Non-community-onset bacteremia was divided into health care-associated and hospital-acquired infections. Health care-associated infection was defined as community-onset infection in a patient who had been admitted to hospital for 2 or more days within the 90 days before the bloodstream infection or in a patient residing in a long-term care facility. Bacteremia with onset $48 \mathrm{~h}$ or more after admission to hospital was classified as hospital-acquired.

Antibiotic therapy was considered appropriate if the bacterial species identified by blood culture was susceptible in vitro to the antibiotic prescribed and if dosing was not subtherapeutic. Antibiotic therapy was considered subtherapeutic if the dose was below the recommended standard dosage, adjusted for any renal dysfunction. ${ }^{9,10}$ The Cockcroft-Gault equation, based on the serum creatinine reported closest to the time of the antibiotic order, was used to estimate creatinine clearance for dose-assessment purposes. ${ }^{11}$ Appropriate therapy included IV antibiotics and oral trimethoprim-sulfamethoxazole and fluoroquinolones, provided the organism was susceptible. ESBL-EK was assumed to be resistant to all cephalosporins (i.e., cefazolin, cefuroxime, cefotaxime, ceftriaxone, ceftazidime, and cefepime) and ampicillin. Combinations of a B-lactam and ß-lactamase inhibitor (e.g., piperacillin-tazobactam) were classified as inappropriate empiric therapy for ESBL-EK bacteremia.

\section{Statistical Analysis}

Data analysis was performed using SPSS software, version 19.0 (IBM, Armonk, New York). Continuous variables were analyzed with a 2 -tailed Student $t$ test if normally distributed and a Mann-Whitney $U$ test if non-normally distributed. Categorical variables were analyzed with the $\chi^{2}$ test or the Fisher exact test and were reported as proportions.

Risk factors were first analyzed by univariate analysis. Previously identified risk factors for ESBL-EK infections (as presented in the literature) were ranked by the authors a priori on the basis of clinical relevance (Table 1). Only the first 4 statistically significant variables were entered (by stepwise forward selection) in the logistic regression model, to ensure reliability of the model and to reduce the risk of overfitting. ${ }^{12}$ Variables compared in the univariate analysis that were deemed clinically significant and that had a $p$ value below 0.05 were considered for inclusion. Each risk factor was added sequentially to the combination found to be most statistically significant. For multivariate analysis, significant variables were reported as odds ratios (ORs) with 95\% confidence intervals (CIs).

Cases (patients with ESBL-EK bacteremia) were compared with controls (patients with non-ESBL-EK bacteremia) for the following variables: appropriateness of empiric antibiotic therapy, time to appropriate antibiotic therapy, length of stay in hospital, admission to ICU, length of stay in the ICU, and in-hospital
Table 1. Hierarchy of Risk Factors for ExtendedSpectrum B-Lactamase Production in Escherichia coli and Klebsiella Species $2,4,5,12-18$

\begin{tabular}{ll}
$\begin{array}{l}\text { Order of } \\
\text { Hierarchy }\end{array}$ & \multicolumn{1}{c}{ Risk Factor } \\
\hline 1 & $\begin{array}{l}\text { Recent antibiotic use (with all antibiotics, all B-lactams } \\
\text { excluding carbapenems, and fluoroquinolones as } \\
\text { subgroups) }\end{array}$ \\
2 & $\begin{array}{l}\text { Travel to Europe or Asia (defined as South or } \\
\text { South East Asia) }\end{array}$ \\
3 & Admission to hospital within the previous 3 months \\
4 & Length of stay in hospital before infection \\
5 & Residence in a long-term care facility \\
6 & Malignancy \\
7 & Diabetes mellitus \\
8 & Mechanical ventilation \\
9 & Charlson score \\
10 & Urinary catheterization \\
11 & Central line catheterization \\
12 & Age $\geq 65$ years \\
\hline
\end{tabular}

mortality. Potential risk factors for ESBL-EK bacteremia were also compared.

\section{RESULTS}

A total of 40 cases and 40 controls were included in the data analysis. Among the cases, E. coli was isolated in 37 patients and Klebsiella species in 3 patients. Given the small number of Klebsiella isolates, all of the ESBL-EK infections were analyzed together. Characteristics of patients in the case and control groups were similar (Table 2). Of the patients with hospital-acquired infections, more cases than controls were admitted under a surgical service (29\% [4/14] versus 9\% [1/11], $p=0.36)$. The majority of infections were thought to have originated from the urinary tract (55\% [22/40] versus 50\% [20/40] for ESBL-EK infections and non-ESBL-EK infections, respectively) (Table 2).

\section{Risk Factors}

Univariate analysis showed significant differences between cases and controls in terms of antibiotic use within the previous 3 months $(p=0.001)$ and admission to hospital within the previous 3 months $(p=0.03)$ (Table 3$)$. Of those who had received antibiotics within the previous 3 months, the difference in use of fluoroquinolones was statistically significant $(p=0.013)$. Univariate analysis also showed that the between-group difference in travel within the previous 3 months was not statistically significant $(p=0.055)$. The 2 risk factors with $p$ values below 0.05 were included in the multivariate analysis. According to multivariate logistic regression, only antibiotic use within the previous 3 months was a significant predictor of bacteremia with an ESBL-producing organism (OR 5.2, 95\% CI 1.6-16.9). 
Table 2. Characteristics of Cases and Controls

\begin{tabular}{|c|c|c|c|c|c|}
\hline \multirow[b]{2}{*}{ Characteristic } & \multicolumn{4}{|c|}{ Group; No. (\%)* } & \multirow[b]{2}{*}{$p$ Value } \\
\hline & \multicolumn{2}{|c|}{$\begin{array}{l}\text { Cases (ESBL-EK) } \\
\quad(n=40)\end{array}$} & \multicolumn{2}{|c|}{$\begin{array}{c}\text { Controls } \\
\text { (non-ESBL-EK) } \\
(n=40)\end{array}$} & \\
\hline Age, years, mean \pm SD & 61.6 & \pm 15.7 & 63.9 & \pm 19.5 & 0.56 \\
\hline Sex, female & 13 & $(32)$ & 18 & $(45)$ & 0.25 \\
\hline Charlson score, median (range) & 2 & $(0-11)$ & 2 & $(0-12)$ & 0.87 \\
\hline $\begin{array}{l}\text { Infecting organism: Escherichia coli } \\
\text { Location of acquisition }\end{array}$ & 37 & (92) & 37 & $(92)$ & $>0.99$ \\
\hline Community onset & 16 & $(40)$ & 20 & $(50)$ & 0.10 \\
\hline Health care-associated & 10 & (25) & 9 & $(22)$ & 0.70 \\
\hline Hospital-acquired & 14 & (35) & 11 & (28) & 0.29 \\
\hline \multicolumn{6}{|l|}{ Hospital location at time of infection } \\
\hline Medical ward & 9 & (64) & 10 & (91) & 0.43 \\
\hline Surgical ward & 4 & (29) & 1 & (9) & 0.36 \\
\hline ICU & 1 & $(7)$ & 0 & (0) & $>0.99$ \\
\hline \multicolumn{6}{|l|}{ Known or suspected origin of infection } \\
\hline Urinary tract & 22 & (55) & 20 & $(50)$ & 0.82 \\
\hline Other & 3 & (8) & 5 & $(12)$ & 0.71 \\
\hline Unknown & 15 & (38) & 15 & (38) & $>0.99$ \\
\hline
\end{tabular}

ESBL-EK = Escherichia coli and Klebsiella species producing extended-spectrum B-lactamase, non-ESBL-EK = Escherichia coli and Klebsiella species not producing extended-spectrum B-lactamase, ICU = intensive care unit, SD = standard deviation.

*Except where indicated otherwise

Table 3. Univariate Analysis of Risk Factors for Acquisition of ESBL-EK

\begin{tabular}{|c|c|c|c|c|c|}
\hline \multirow{3}{*}{$\begin{array}{l}\text { Risk Factor } \\
\text { Prior antibiotic use (previous } 3 \text { months)* }\end{array}$} & \multicolumn{4}{|c|}{ Group; No. (\%)* } & \multirow{3}{*}{$\begin{array}{l}p \text { Value } \\
0.001 \neq\end{array}$} \\
\hline & \multicolumn{2}{|c|}{$\begin{array}{l}\text { Cases (ESBL-EK) } \\
\quad(n=40)\end{array}$} & \multicolumn{2}{|c|}{$\begin{array}{c}\text { Controls } \\
\text { (non-ESBL-EK) } \\
(n=40)\end{array}$} & \\
\hline & 19 & $(48)$ & 5 & $(12)$ & \\
\hline B-Lactamst & 9 & $(22)$ & 4 & (10) & $0.23 \neq$ \\
\hline Fluoroquinolones & 11 & $(28)$ & 2 & (5) & $0.013 \neq$ \\
\hline Prior travel (previous 3 months) & 5 & $(12)$ & 0 & $(0)$ & $0.055 \S$ \\
\hline $\begin{array}{l}\text { Prior hospital admission } \\
\text { (previous } 3 \text { months) }\end{array}$ & 17 & $(42)$ & 8 & $(20)$ & $0.03 \ddagger$ \\
\hline Hospital stay $>14$ days & 7 & $(18)$ & 7 & (18) & $>0.99 \neq$ \\
\hline Residence in long-term care facility & 2 & (5) & 7 & (18) & $0.15 \S$ \\
\hline Current malignancy & 11 & $(28)$ & 13 & $(32)$ & $0.63 \ddagger$ \\
\hline Diabetes mellitus & 12 & (30) & 12 & (30) & $>0.99 \neq$ \\
\hline Mechanical ventilation & 3 & (8) & 1 & $(2)$ & $0.62 \S$ \\
\hline Charlson score $>2$ & 16 & $(40)$ & 17 & $(42)$ & $0.82 \ddagger$ \\
\hline Urinary catheterization & 10 & (25) & 10 & (25) & $>0.99 \neq$ \\
\hline Central line catheterization & 14 & (35) & 8 & (20) & $0.13 \neq$ \\
\hline Age $\geq 65$ years old & 18 & $(45)$ & 23 & (58) & $0.26 \neq$ \\
\hline \multicolumn{6}{|c|}{$\begin{array}{l}\text { ESBL-EK = Escherichia coli and Klebsiella species producing extended-spectrum B-lactamase, } \\
\text { non-ESBL-EK = Escherichia coli and Klebsiella species not producing extended-spectrum } \\
\text { B-lactamase. } \\
\text { *In each group, one patient received both B-lactam and fluoroquinolone therapy. } \\
\text { tExcludes carbapenems. } \\
\text { ‡By } \chi^{2} \text { test. } \\
\text { §By Fisher exact test. }\end{array}$} \\
\hline
\end{tabular}




\section{Appropriateness of Antibiotic Therapy}

Controls were more likely to receive appropriate empiric antibiotic therapy initially (88\% [35/40] versus $15 \%$ [6/40], $p<0.001$ ) (Table 4). Among these patients with initial prescription of appropriate empiric antibiotic therapy, there was no significant difference in the time to receipt of appropriate therapy between cases and controls (median 0.32 days versus 0.15 days, $p=0.63$ ). However, the overall median length of time to administration of appropriate antibiotic therapy (including patients whose initial therapy was inappropriate) was 2.42 days for cases (range 0.01-8.57) and 0.17 days for controls (range 0.00-5.17) $(p<0.001)$. Four cases and 2 controls never received appropriate antibiotic therapy. Among the cases, the reasons for never receiving appropriate antibiotic therapy were discharge on fluoroquinolone therapy before culture results and/or susceptibilities became available $(n=2)$, insufficient dose $(n=1)$, and death before culture results became available $(n=1)$. Among the controls, the reasons for never receiving appropriate antibiotic therapy were insufficient dose $(n=1)$ and discharge from hospital without antibiotic therapy $(n=1)$.

\section{Outcomes}

There were no significant differences between cases and controls in terms of length of stay in hospital, admission to the intensive care unit, length of stay in the intensive care unit (if applicable), or in-hospital mortality (Table 5). Postinfection length of stay was longer in cases than in controls (15.5 days versus 8.5 days, $p=0.12$ ), as was length of stay in the ICU (6.5 days versus 1.0 day, $p=0.094$ ), but these differences were nonsignificant.

Among the patients with ESBL-EK bacteremia, there were no significant differences in hospital or ICU length of stay, admission to the ICU, or in-hospital mortality between those for whom appropriate and inappropriate empiric antibiotic therapy was prescribed (data not shown).

\section{Resistance Rates}

For all non-ß-lactam agents examined except amikacin, resistance rates were higher for isolates producing ESBLs than for isolates not producing ESBLs. The largest difference in resistance rates was observed with ciprofloxacin (90\% [36/40] versus $12 \%$ [5/40] for cases and controls, respectively). Resistance rates were also higher for isolates producing ESBL for gentamicin (55\% [22/40] versus 10\% [4/40]), tobramycin (48\% [19/40] versus $8 \%[3 / 40])$, and trimethoprim-sulfamethoxazole $(80 \%$ [32/40] versus $20 \%$ [8/40]).

\section{DISCUSSION}

Several factors that increase the risk for infection with an ESBL-producing organism have been identified in previous reports. The risk factors previously identified include, but are not limited to, travel, recent antibiotic use, hospital stay of longer than 2 weeks preceding the infection, age 65 years or older, and prior hospital admission. ${ }^{2,4,5,13-19}$ Previously published casecontrol studies have varied with respect to geographic location, types of infections and/or organisms included, and site where the infection was acquired. However, few Canadian studies examining risk factors or outcomes associated with infection with these organisms have been conducted. ${ }^{4-6}$ The study reported here adds to the current body of literature by identifying local risk factors for acquiring an ESBL infection at a single Canadian tertiary care institution with a relatively low prevalence of ESBL-EK bacteremia. During the period of the study, the prevalence of ESBL-EK bacteremia at this centre was less than $4 \%$ of all cases of bacteremia caused by E. coli or Klebsiella species.

Table 4. Antibiotic Therapy for Cases and Controls

\begin{tabular}{|c|c|c|c|}
\hline \multirow[b]{2}{*}{ Aspect of Therapy } & \multicolumn{2}{|c|}{ Group; No. (\%) or Median (Range) } & \multirow[b]{2}{*}{$p$ Value } \\
\hline & $\begin{array}{l}\text { Cases (ESBL-EK) } \\
(n=40)\end{array}$ & $\begin{array}{c}\text { Controls } \\
\text { (non-ESBL-EK) } \\
(n=40) \\
\end{array}$ & \\
\hline $\begin{array}{l}\text { Initial prescription of appropriate } \\
\text { empiric antibiotic therapy }\end{array}$ & $6 \quad(15)$ & $35 \quad(88)$ & $<0.001^{\star}$ \\
\hline $\begin{array}{l}\text { Time to initial prescription of } \\
\text { appropriate empiric antibiotic } \\
\text { therapy, days }\end{array}$ & $0.32 \quad(0.01-3.72)$ & $0.15 \quad(0.00-2.10)$ & $0.63+$ \\
\hline $\begin{array}{l}\text { Never received appropriate } \\
\text { antibiotic therapy }\end{array}$ & $4 \quad(10)$ & $2 \quad(5)$ & $0.68+$ \\
\hline $\begin{array}{l}\text { Overall time to first dose of } \\
\text { appropriate antibiotic therapy, } \neq \text { days }\end{array}$ & $2.42 \quad(0.01-8.57)$ & $0.17 \quad(0.00-5.17)$ & $<0.001 \S$ \\
\hline \multicolumn{4}{|c|}{$\begin{array}{l}\text { ESBL-EK = Escherichia coli and Klebsiella species producing extended-spectrum B-lactamase, } \\
\text { non-ESBL-EK = Escherichia coli and Klebsiella species not producing extended-spectrum B-lactamase. } \\
\text { *By } \chi^{2} \text { test. } \\
\text { †By Mann-Whitney test. } \\
\text { †For all patients, including those who initially received inappropriate therapy. } \\
\text { §By Fisher exact test. }\end{array}$} \\
\hline
\end{tabular}


This single copy is for your personal, non-commercial use only.

For permission to reprint multiple copies or to order presentation-ready copies for distribution, contact CJHP at cjhpedit@cshp.ca

Table 5. Outcomes for Cases and Controls

\begin{tabular}{|c|c|c|c|}
\hline \multirow[b]{2}{*}{ Outcome } & \multicolumn{2}{|c|}{ Group; No. (\%) or Median (Range) } & \multirow[b]{2}{*}{$p$ Value } \\
\hline & $\begin{array}{l}\text { Cases (ESBL-EK) } \\
\quad(n=40)\end{array}$ & $\begin{array}{c}\text { Controls } \\
\text { (non-ESBL-EK) } \\
(n=40)\end{array}$ & \\
\hline $\begin{array}{l}\text { Length of stay in hospital after } \\
\text { positive result on blood culture, days }\end{array}$ & $15.5(1-123)$ & $8.5(1-217)$ & $0.12^{*}$ \\
\hline Admission to ICU, & $10(25)$ & $6(15)$ & $0.26+$ \\
\hline Length of stay in ICU, days & $6.5(1-43)$ & $1.0(1-13)$ & $0.094^{*}$ \\
\hline Death in hospital & $7(18)$ & $6(15)$ & $0.76 t$ \\
\hline \multicolumn{4}{|c|}{$\begin{array}{l}\text { ESBL-EK = Escherichia coli and Klebsiella species producing extended-spectrum B-lactamase, } \\
\text { non-ESBL-EK = Escherichia coli and Klebsiella species not producing extended-spectrum } \\
\text { B-lactamase, ICU = intensive care unit. } \\
\text { *By Mann-Whitney test. } \\
\text { †By } \chi^{2} \text { test. }\end{array}$} \\
\hline
\end{tabular}

In the current study, univariate analysis identified recent antibiotic use (within the past 3 months) and recent hospital admission (within the past 3 months) as being associated with acquisition of ESBL-EK bacteremia. However, after multivariate analysis, only previous antibiotic use was identified as an independent risk factor. These 2 risk factors may be related, as a patient is more likely to have received antibiotic therapy with prior hospital admission.

The finding that antibiotic use within the past 3 months was an independent risk factor for ESBL-EK bacteremia is similar to the results of other investigations. Garnacho-Montero and others $^{20}$ found that previous exposure to antibiotics, and hence the potential for emergence of resistant strains, is a risk factor that may increase the likelihood of a patient receiving inadequate empiric antibiotic therapy. Those authors suggested that previous antibiotic use may be a reason to broaden the empiric regimen to cover multidrug-resistant strains, ${ }^{20}$ which may include organisms producing ESBLs. As such, clinicians should identify and consider prior antibiotic therapy for all patients, to help determine the risk of ESBL-EK bacteremia and to help direct empiric antibiotic therapy in patients with signs and/or symptoms of infection.

Because travel within the past 3 months showed a trend toward being a risk factor for ESBL-EK bacteremia (12\% versus $0 \%, p=0.055)$, the multivariate logistic regression was repeated post hoc using all risk factors with $p$ values below 0.10 (i.e., antibiotic use and fluoroquinolone use within the previous 3 months, prior travel, and prior hospital admission). In this repeat analysis, travel to Europe or Asia was not identified as an independent risk factor for acquiring ESBL bacteremia; as before, only previous antibiotic use was found to be an independent risk factor (OR 6.3, 95\% CI 2.1-19.5). This finding differs from the results of previous studies, which identified travel as a significant risk factor for ESBL-EK bacteremia. ${ }^{5,18,21,22}$ The lack of significance in the current study is likely due to the small number of patients with a documented history of travel to predefined areas within the previous 3 months (5 out of 80 study patients). In a prospective study examining foreign travel as a risk factor for colonization with ESBL-producing Enterobacteriaceae, travel to India was associated with the highest proportion of patients returning with ESBL-producing E. coli strains. ${ }^{21}$ Travel to Asia and the Middle East was also associated with a nonsignificant incidence of colonization. Although travel to the Middle East was not included in the current analysis, none of the patients in this study were recorded as having travelled to that area. Despite these findings, all patients presenting with infections should be questioned about foreign travel, to allow selection of appropriate empiric antibiotic therapy.

Bacteria producing ESBLs are generally considered resistant to oxyimino-cephalosporins, including cefotaxime, ceftazidime, ceftriaxone, cefuroxime, and cefepime, as well as monobactams, such as aztreonam. As such, in addition to the higher rates of cross-resistance of ESBL-EK organisms to non- $\beta$-lactam agents such as fluoroquinolones, aminoglycosides, and trimethoprimsulfamethoxazole (as observed in this study), it is not surprising that the cases in this study were less likely than controls to receive appropriate empiric antibiotic therapy. In addition, the time to appropriate antibiotic therapy was longer for those with ESBLEK bacteremia than for those with non-ESBL-EK bacteremia (median 2.42 days versus 0.17 days, $p<0.001$ ). This difference was likely due to the time-consuming testing procedures required to identify and determine susceptibilities for isolates producing ESBLs and the resultant delays in changing to more appropriate therapy. Similarly, in a case-control study conducted across 8 Canadian hospitals, a longer time to appropriate antibiotic therapy was observed for cases (patients with clinical isolates of ESBL-producing or ampicillin class $\mathrm{C}$-producing organisms) (median 2.8 days versus 1.2 days, $p=0.05$ ). ${ }^{4}$ Neither the current study nor the previous one $e^{4}$ identified any significant adverse clinical outcomes, despite the difference in rates of prescription of appropriate empiric antibiotics and the delay to initiation of antibiotics with in vitro susceptibility. Also similar to the current study, Chaubey and others ${ }^{6}$ did not observe a significant difference in case fatality rate between patients who received adequate antibiotic therapy and those inadequately treated at $48 \mathrm{~h}^{6}$ 
The efficacy of piperacillin-tazobactam in the treatment of ESBL infections is controversial. ${ }^{23}$ In this study, piperacillintazobactam was considered inappropriate antibiotic therapy, in accordance with Ontario's external quality assessment recommendations. ${ }^{24}$ Because of this controversy, however, outcomes were also compared between cases and controls with piperacillintazobactam being considered appropriate therapy; in addition, cases who received other appropriate empiric antibiotic therapy (i.e., ciprofloxacin, meropenem) were compared with those who received piperacillin-tazobactam. In both comparisons, the length of stay following positive result on blood culture was longer, although not significantly so, in the piperacillin-tazobactam group (data not shown). These results are similar to those published by Chaubey and others, ${ }^{6}$ who reported that patients who received empiric treatment with a -lactam/ß-lactamase inhibitor combination had a nonsignificantly greater mortality rate (37.5\% versus $18.9 \%, p=0.063)$. Of interest, in both the current study and the study by Chaubey and others, ${ }^{6}$ a urinary source was identified as the cause of the bacteremia in about half of the patients. Some clinicians may consider ß-lactam/ß-lactamase inhibitor combinations adequate therapy in such cases, given the possible lower inoculum of bacteria. ${ }^{23}$

Many studies have attempted to examine the potential relationship between presence of ESBL and death. . $3,17,25-29^{2}$ Contrary to these previous studies, the current study showed no increase in the risk of death associated with infections due to ESBL-producing bacteria. There is a lack of consensus in the literature regarding the effect of ESBL bacteremia on mortality, likely because of the small sample sizes of individual studies. However, a meta-analysis showed a statistically significant association between presence of ESBL and mortality. ${ }^{26}$

Although not statistically significant, perhaps because of the small sample size, length of stay in hospital was longer, the proportion of patients admitted to the ICU was higher, and the length of stay in the ICU was higher for cases (patients with ESBL-EK bacteremia) than for controls (patients with non-ESBL-EK bacteremia). Ofner-Agostini and others ${ }^{4}$ also observed that the postinfection length of stay was longer for cases than for controls, although not significantly so.

Appropriate selection of empiric therapy is a key principle of antimicrobial stewardship. This study identified key risk factors that may increase the likelihood of a seriously ill patient being infected with ESBL-EK. Clinicians should question patients about recent antibiotic use, recent admissions to hospital, and any recent travel (where "recent" means within the previous 3 months). If 2 or more such risk factors are present, the empiric use of a carbapenem may be recommended according to the severity of the presenting illness.

Certain limitations are inherent to the topic of this study and the study design used. Given the small number of infections with Klebsiella species, data for all organisms producing ESBL were analyzed as one group. However, the validity of this gener- alization was not determined. Because of the low incidence of ESBL-EK bacteremia at the study institution, it is possible that significant risk factors were missed in the multivariate analysis. For example, only 5 of the 80 study patients had a history of travel to predefined areas. In addition, the small sample size may have limited the ability to observe statistically significant differences in patient outcomes. Given the retrospective nature of this study, the authors relied on documentation in patients' charts for information about risk factors. It was assumed that absence of documentation about a particular risk factor signified absence of that risk factor, despite the limitations of this assumption. Furthermore, it is unclear how using different periods of prior antibiotic use and travel history would affect the results. Because patients' infection-related severity of illness at the time of admission was not assessed or considered, caution should be used in interpreting outcomes such as length of stay in hospital, admission to the ICU, length of stay in the ICU, and mortality. Information about ICU outcomes should not be generalized, as only one patient was admitted to the ICU during an episode of bacteremia. Finally, the data analyzed here date back as far as 2005 and may not reflect current resistance patterns or the incidence of ESBL-EK bacteremia at the study institution.

\section{CONCLUSION}

In this era of increasing antibiotic resistance, clinicians are faced with challenges in providing adequate initial antibiotic therapy. This study identified risk factors for, and examined outcomes of patients with, ESBL-EK bacteremia. Previous antibiotic use was found to be a significant independent risk factor for bacteremia due to ESBL-EK. Although the effect of initial antibiotic therapy on outcomes of ESBL-EK bacteremia remains controversial, a patient's history of antibiotic use remains an important consideration in the selection of empiric therapy.

\section{References}

1. Mazzulli T. Canadian patterns of antimicrobial resistance: overview of current trends related to hospital pathogens. Can J Infect Dis Med Microbiol. 2006;17 Suppl B:3B-5B.

2. Pitout JDD. Infections with extended-spectrum beta-lactamase-producing Enterobacteriaceae: changing epidemiology and drug treatment choices. Drugs. 2010;70(3):313-33.

3. Denisuik AJ, Lagacé-Wiens PRS, Pitout JD, Mulvey MR, Simmer PJ, Tailor F, et al. Molecular epidemiology of extended-spectrum ß-lactamase-, AmpC ß-lactamase- and carbapenemase-producing Escherichia coli and Klebsiella pneumoniae isolated from Canadian hospitals over a 5 year period: CANWARD 2007-11. J Antimicrob Chemother. 2013;68 Suppl 1:i57-65.

4. Ofner-Agostini M, Simor A, Mulvey M, McGeer A, Hirji Z, McCracken $\mathrm{M}$, et al. Risk factors for and outcomes associated with clinical isolates of Escherichia coli and Klebsiella species resistant to extended-spectrum cephalosporins among patients admitted to Canadian hospitals. Can J Infect Dis Med Microbiol. 2009;20(3):e43-8.

5. Laupland KB, Church DL, Vidakovich J, Mucenski M, Pitout JDD. Community-onset extended-spectrum beta-lactamase (ESBL) producing Escherichia coli: importance of international travel. J Infect. 2008;57(6): 441-8.

6. Chaubey VP, Pitout JDD, Dalton B, Ross T, Church DL, Gregson DB, et al. Clinical outcome of empiric antimicrobial therapy of bacteremia due to 
extended-spectrum beta-lactamase producing Escherichia coli and Klebsiella pneumoniae. BMC Res Notes. 2010;3:116.

7. Performance standards for antimicrobial susceptibility testing (M100-S23): 23rd Informational Supplement. Wayne (PA): Clinical and Laboratory Standards Institute; 2013.

8. Charlson ME, Pompei P, Ales KL, MacKenzie CR. A new method of classifying prognostic comorbidity in longitudinal studies: development and validation. J Chronic Dis. 1987;40(5):373-83.

9. Aronoff GR, editor. Drug prescribing in renal failure: dosing guidelines for adults and children. 5th ed. Philadelphia (PA): American College of Physicians; 2007.

10. Repchinsky C, editor-in-chief. Compendium of pharmaceuticals and specialties. Ottawa (ON): Canadian Pharmacists Association; 2010.

11. Cockcroft DW, Gault MH. Prediction of creatinine clearance from serum creatinine. Nephron. 1976;16(1):31-41.

12. Harrell FE. Regression modeling strategies: with applications to linear models, logistic regression, and survival analysis. Nashville (TN): Springer; 2001.

13. Ho PL, Chan WM, Tsang KT, Wong SS, Young K. Bacteremia caused by Escherichia coli producing extended-spectrum beta-lactamase: a case-control study of risk factors and outcomes. Scand J Infect Dis. 2002;34(8):567-73.

14. Ben-Ami R, Rodríguez-Baño J, Arslan H, Pitout JD, Quentin C, Calbo ES, et al. A multinational survey of risk factors for infection with extendedspectrum beta-lactamase-producing Enterobacteriaceae in nonhospitalized patients. Clin Infect Dis. 2009;49(5):682-90.

15. Rodríguez-Baño J, Picón E, Gijón P, Hernández JR, Ruíz M, Peña C, et al. Community-onset bacteremia due to extended-spectrum beta-lactamaseproducing Escherichia coli: risk factors and prognosis. Clin Infect Dis. 2010;50(1):40-8.

16. Silva N, Oliveira M, Bandeira AC, Brites C. Risk factors for infection by extended-spectrum beta-lactamase producing Klebsiella pneumoniae in a tertiary hospital in Salvador, Brazil. Braz J Infect Dis. 2006;10(3):191-3.

17. Kang CI, Kim SH, Kim DM, Park WB, Lee KD, Kim HB, et al. Risk factors for and clinical outcomes of bloodstream infections caused by extended-spectrum beta-lactamase-producing Klebsiella pneumoniae. Infect Control Hosp Epidemiol. 2004;25(10):860-7.

18. Kuster SP, Hasse B, Huebner V, Bansal V, Zbinden R, Ruef C, et al. Risk factors for infections with extended-spectrum beta-lactamase-producing Escherichia coli and Klebsiella pneumoniae at a tertiary care university hospital in Switzerland. Infection. 2010;38(1):33-40.

19. Lee SO, Lee ES, Park SY, Seo YH, Cho YK. Reduced use of third-generation cephalosporins decreases the acquisition of extended-spectrum betalactamase-producing Klebsiella pneumoniae. Infect Control Hosp Epidemiol. 2004;25(10):832-7.

20. Garnacho-Montero J, Garcia-Garmendia L, Barrero-Almodovar A, JimenzJimenez FJ, Perez-Paredes C, Ortiz-Leyba C. Impact of adequate empirical antibiotic therapy on the outcome of patients admitted to the intensive care unit with sepsis. Crit Care Med. 2003;31(12):2742-51.

21. Tängdén T, Cars O, Melhus $\AA$, Löwdin E. Foreign travel is a major risk factor for colonization with Escherichia coli producing CTX-M-type extended-spectrum beta-lactamases: a prospective study with Swedish volunteers. Antimicrob Agents Chemother. 2010;54(9):3564-8.

22. Tham J, Odenholt I, Walder M, Brolund A, Ahl J, Melander E. Extendedspectrum beta-lactamase-producing Escherichia coli in patients with travellers' diarrhoea. Scand J Infect Dis. 2010;42(4):275-80.
23. Perez F, Bonomo RA. Can we really use ß-lactam/ß-lactam inhibitor combinations for the treatment of infections caused by extended-spectrum ß-lactamase-producing bacteria? Clin Infect Dis. 2012;54(2):175-7.

24. External quality assessment: Bacteriology. Consensus practice recommendations - antimicrobial susceptibility testing and reporting on bacteriology specimens. Toronto (ON): Quality Management Program—Laboratory Services; 2007 Nov 11 [revised 2013 May 29].

25. Schwaber MJ, Navon-Venezia S, Kaye KS, Ben-Ami R, Schwartz D, Carmeli Y. Clinical and economic impact of bacteremia with extendedspectrum-beta-lactamase-producing Enterobacteriaceae. Antimicrob Agents Chemother. 2006;50(4):1257-62.

26. Schwaber MJ, Carmeli Y. Mortality and delay in effective therapy associated with extended-spectrum beta-lactamase production in Enterobacteriaceae bacteraemia: a systematic review and meta-analysis. J Antimicrob Chemother. 2007;60(5):913-20.

27. Kang CI, Song JH, Chung DR, Peck KR, Ko KS, Yeom JS, et al.; Korean Network for Study of Infectious Diseases (KONSID). Risk factors and treatment outcomes of community-onset bacteraemia caused by extendedspectrum beta-lactamase-producing Escherichia coli. Int J Antimicrob Agents. 2010;36(3):284-7

28. Lee SY, Kotapati S, Kuti JL, Nightingale CH, Nicolau DP. Impact of extended-spectrum beta-lactamase-producing Escherichia coli and Klebsiella species on clinical outcomes and hospital costs: a matched cohort study. Infect Control Hosp Epidemiol. 2006;27(11):1226-32.

29. Frakking FNJ, Rottier WC, Dorigo-Zetsma JW, van Hattem JM, van Hees BC, Kluytmans JAJW, et al. Appropriateness of empirical treatment and outcome in bacteremia caused by extended-spectrum- $\beta$-lactamase-producing bacteria. Antimicrob Agents Chemother. 2013;57(7):3092-9.

My-Linh Nguyen, BScPhm, ACPR, is with the Department of Pharmacy, The Ottawa Hospital, Ottawa, Ontario

Baldwin Toye, MD, FRCPC, is with the Divisions of Microbiology and Infectious Diseases, The Ottawa Hospital, and the Faculty of Medicine, University of Ottawa, Ottawa, Ontario.

Salmaan Kanji, PharmD, is with the Ottawa Hospital Research Institute, Ottawa, Ontario.

Rosemary Zvonar, BScPhm, ACPR, FCSHP, is with the Department of Pharmacy, The Ottawa Hospital, Ottawa, Ontario.

Competing interests: Baldwin Toye has received a grant from Merck for participation in a research study unrelated to this article. Rosemary Zvonar has received personal fees from Pfizer Canada and Merck Canada for projects unrelated to this article. No competing interests declared by My-Linh Nguyen and Salmaan Kanji.

\section{Address correspondence to:}

My-Linh Nguyen

Department of Pharmacy

The Ottawa Hospital

501 Smyth Road

Ottawa ON K1H8L6

e-mail: mylnguyen@toh.on.ca 